\section{BIOSYSTEMATIC ANALYSIS OF THE CYSTOPTERIS TENNESSEENSIS (DRYOPTERIDACEAE) COMPLEX $^{1}$}

\author{
Christopher H. Haufler, ${ }^{2}$ \\ Michael D. Windham ${ }^{2,3}$ and \\ Thomas A. Ranker ${ }^{4}$
}

\begin{abstract}
The allotetraploid Cystopteris tennesseensis and its putative diploid progenitors, C. bulbifera and C. protrusa, constitute the C. tennesseensis complex. Although previous studies provided evidence of morphological, ecological, and chromosomal differences among the members of this complex, puzzling morphological variability precluded consistent identification and treatment of the taxa. The current study combined morphometric analyses with surveys of chromosomal, isozymic, and gametophytic features and supported past treatments of the complex as three separate species. The diploids shared no allozymes for the nine enzymes examined, and meiotic analyses of triploid hybrids with $C$. tennesseensis provided additional evidence that the diploid genomes are nonhomologous. Because $C$. tennesseensis has a relatively narrow range and contains isozymic profiles that are consistently additive of diploid patterns, we suggest that this allopolyploid is a relatively young species. Isozymic variation in the tetraploid parallels that observed in the diploids, implying that genetic variability was introduced through recurrent hybridization. Analyses of isozymic data and gametophytic features indicated that the diploids outcross frequently and thus may form hybrids readily when sympatric with the tetraploid. In part because of these characteristics, precise identification of species and hybrids in this complex is difficult and depends on evaluation of cryptic features.
\end{abstract}

The cosmopolitan genus Cystopteris Bernh. has been called "perhaps the most formidable biosystematic problem in the ferns" (Lovis, 1977, p. 356). Although Cystopteris species are primarily north temperate and therefore readily accessible to pteridologists, complex patterns of morphological variation have thwarted satisfactory taxonomic treatments. The most recent monograph (Blasdell, 1963) recognized ten species in two subgenera. Subgenus Acystopteris includes the Asian species $C$. japonica and $C$. tenuisecta, which are so distinctive that some have placed them in a separate genus (Nakai, 1933; Pichi-Sermolli, 1977). Blasdell divided the remaining species (all in subg. Cystopteris) into two sections based on the pattern of vein termination in the leaves. Species having veins directed into teeth were placed in sect. Cystopteris, while those with veins directed into sinuses were assigned to sect. Emarginatae. Blasdell encountered variability for this vein termination character in some specimens and suggested that such anomalies could result from introgression. Lovis (1977), on the other hand, considered it more likely that venation features are not as stable in some species as in others and should not be used to define sections.

Our observations suggested that Lovis was correct and, rather than organizing the North American Cystopteris species into morphologically based sections, we have chosen to concentrate on interactive species complexes involving allopolyploid species and their putative diploid progenitors. One

${ }^{1} \mathrm{CHH}$ is profoundly indebted to Alice and Rolla Tryon for providing the opportunity through a Gray Herbarium Postdoctoral Fellowship to delve deeply into the world of ferns and for passing on by example their infectious curiosity about these marvelous plants. This research was supported by the National Science Foundation. We thank Donald Burke, Cara Burres, Lori Hanson, Warren Hauk, Carol Kuhn, Robin Prentice, and Eric Rabe for technical assistance, David Barrington for drawing Figure 1, and the officers of the following herbaria for loans of specimens: COLO, DAO, GH, ILLS, IND, KANU, KE, KY, MICH, MIL, MO, NY, PAG, OAC, OS, SIU, TENN, UARK, US, VPI, VT, and WIS. We are especially thankful to Ralph Brooks and Ron McGregor of KANU for housing the many hundreds of specimens. Living specimens were generously supplied by D. M. Britton, R. E. Brooks, S. C. Churchill, J. J. Doyle, R. C. Moran, T. Reeves, D. E. Soltis, W. C. Taylor, C. K. Teale, and W. H. Wagner.

${ }^{2}$ Department of Botany, University of Kansas, Lawrence, Kansas 66045, U.S.A.

${ }^{3}$ Present Address: Utah Museum of Natural History, University of Utah, Salt Lake City, Utah 8411 2, U.S.A.

${ }^{4}$ University of Hawaii, Hawaiian Evolutionary Biology Program, Honolulu, Hawaii 96822, U.S.A.

Ann. Missouri Bot. Gard. 77: 314-329. 1990. 
such complex centers on $C$. tennesseensis, a species first recognized by Shaver (1950) who described it as a hybrid between $C$. bulbifera and C. protrusa. In 1954 Shaver developed an extended discussion of the morphology and ecology of the complex which still stands as an excellent summary of the natural history of this difficult group.

From the moment it was named, there was disagreement concerning the proper status and disposition of C. tennesseensis. McGregor (1950), in collaboration with $\mathrm{C}$. A. Weatherby, reduced this species to a variety of $C$. fragilis. In addition, citing specimens that did not conform to the protologue of $C$. fragilis var. tennesseensis and that seemed to be close to Weatherby's $C$. fragilis $\mathrm{f}$. simulans, McGregor recognized $C$. fragilis var. simulans. This approach seemed justified because some specimens tend to bridge the morphological gap between these two varieties as well as between C. fragilis var. fragilis and C. fragilis var. tennesseensis. However, Blasdell (1963) revealed $C$. tennesseensis as a tetraploid with $n=84$ chromosomes. His analysis showed that hybridization between $C$. protrusa and $C$. bulbifera was the most reasonable explanation for the origin of this tetraploid. Therefore, Blasdell resurrected $C$. tennesseensis as a species, including the former $C$. fragilis var. simulans.

The subtlety of morphological features separating the species as well as the continued discovery of intermediates has perpetuated the systematic confusion of the $C$. tennesseensis complex. Even though the accumulated data demonstrate conclusively that $C$. tennesseensis is isolated from its congeners, this tetraploid has not been widely accepted as a distinct species. As recently as 1982 , Moran (1982, p. 94) found in a study of Cystopteris specimens from Illinois that "all 90 herbarium specimens of $C$. tennesseensis . . were originally misidentified."

In this paper, we report a series of analyses designed to investigate the patterns and the processes behind the systematic confusion in C. tennesseensis. We describe studies of biogeography, morphology, chromosomes, and isozymes that clarify the origin and current status of C. tennesseensis and its progenitor diploids.

\section{Materials ANd MethodS}

Observations of morphological variability, geographic distribution, and habitat diversity were obtained from surveys of herbarium specimens. If specific locality data were supplied, collection sites were plotted by county and used to obtain distri-
TABLE 1. Mean spore sizes and standard deviations calculated by measuring the long axis of 25 spores. Specimens whose ploidy level has been verified by meiotic chromosome squashes are indicated by asterisks. States listed in parentheses are those from which the specimens were collected.

\begin{tabular}{|c|c|}
\hline C. bulbifera (Illinois) & $37.48 \pm 1.949$ \\
\hline C. bulbifera* (Oklahoma) & $35.21 \pm 3.408$ \\
\hline C. bulbifera* (Arizona) & $36.27 \pm 2.560$ \\
\hline C. bulbifera* (Indiana) & $35.96 \pm 2.325$ \\
\hline C. bulbifera* (Ohio) & $39.81 \pm 2.944$ \\
\hline C. bulbifera (Ohio) & $35.71 \pm 3.038$ \\
\hline C. bulbifera (Kentucky) & $34.39 \pm 1.764$ \\
\hline \multirow[t]{2}{*}{ C. bulbifera (Indiana) } & $36.78 \pm 2.336$ \\
\hline & $=36.45 \pm 1.650$ \\
\hline C. protrusa (Illinois) & $33.65 \pm 1.788$ \\
\hline C. protrusa* (Kansas) & $35.22 \pm 4.714$ \\
\hline C. protrusa (Missouri) & $33.33 \pm 2.421$ \\
\hline C. protrusa* (Kansas) & $30.77 \pm 1.868$ \\
\hline C. protrusa* (Kansas) & $30.98 \pm 2.260$ \\
\hline C. protrusa* (Michigan) & $33.21 \pm 2.332$ \\
\hline \multirow{2}{*}{ C. protrusa* (North Carolina) } & $34.22 \pm 3.042$ \\
\hline & $3.05 \pm 1.634$ \\
\hline C. tennesseensis* (Kansas) & $40.02 \pm 3.250$ \\
\hline C. tennesseensis* (Missouri) & $41.40 \pm 1.907$ \\
\hline C. tennesseensis* (Illinois) & $41.29 \pm 2.416$ \\
\hline \multirow{2}{*}{ C. tennesseensis* (Arkansas) } & $40.65 \pm 2.084$ \\
\hline & $=40.84 \pm 0.639$ \\
\hline
\end{tabular}

butional information. When the gross morphology of specimens was not sufficient to assign them readily to species, spores were removed and mounted in Permount on glass microscope slides. The longest diameter of the monolete spores (Table 1) and evidence of abortion (e.g., shrunken or malformed spores) was noted. Spore slides were placed in envelopes and attached to herbarium sheets.

To supplement herbarium collections and supply living material for chromosomal, isozymic, and common garden morphological comparisons, specimens were collected over much of the range of the genus in North America and were donated as noted in footnote 1. Living collections were maintained in the University of Kansas greenhouses. Collection sites for materials used in this study are listed in Table 2.

Ecologically induced morphological variation may obscure genetically based species distinctions. Therefore, we conducted discriminant analyses of morphological variation based on plants cultivated in the greenhouse. All individual plants were identified and assigned to a group on the basis of chromosome number and isozymic composition. Fea- 
TABLE 2. Locality data for collections providing material for electrophoretic and cytogenetic analyses. Asterisks indicate localities used for population genetic analyses (see Table 4).

\begin{tabular}{|c|c|c|}
\hline Locality & Collector & $\begin{array}{c}\text { Chromosome } \\
\text { number } \\
\text { verified? }\end{array}$ \\
\hline \multicolumn{3}{|l|}{ Cystopteris bulbifera } \\
\hline Arizona: Coconino Co., Rio de Flag & Windham 194 & Yes, 42II \\
\hline Arizona: Coconino Co., Oak Creek Canyon & Windham 314 & Yes, 42II \\
\hline Arizona: Coconino Co., Lower West Fork & W. H. Wagner 82113 & Yes, 42II \\
\hline Indiana: Fountain Co., Portland Arch* & C. H. Haufler \& R. C. Moran s.n. & No \\
\hline Indiana: Jefferson Co., Clifty Falls & C. H. Haufler \& R. C. Moran s.n. & No \\
\hline Indiana: Monroe Co., Cedar Bluffs* & C. H. Haufler \& R. C. Moran s.n. & No \\
\hline Kentucky: Powell Co., Natural Bridge* & C. H. Haufler \& R. C. Moran s.n. & No \\
\hline Ohio: Adams Co., near Stout* & C. H. Haufler \& R. C. Moran s.n. & Yes, 42II \\
\hline Oklahoma: Ottawa Co., Dripping Springs & C. H. Haufler \& C. K. Teale s.n. & Yes, 42II \\
\hline Wisconsin: Door Co., Peninsula State Park & W. C. Taylor s.n. & Yes, 42II \\
\hline \multicolumn{3}{|l|}{ C. protrusa } \\
\hline Iowa: Fremont Co., SW of Sidney & R. E. Brooks 14929 & Yes, 42II \\
\hline $\begin{array}{l}\text { Illinois: Cook Co., McGinness Slough } \\
\text { Conservation Area }\end{array}$ & R. C. Moran s.n. & No \\
\hline Illinois: Union Co., Shawnee National Forest & C. H. Haufler s.n. & Yes, 42II \\
\hline Indiana: Monroe Co., Cedar Bluffs* & C. H. Haufler \& R. C. Moran s.n. & No \\
\hline Indiana: Monroe Co. Cascades Park* & C. H. Haufler s.n. & No \\
\hline Indiana: Monroe Co., Farr Road* & C. H. Haufler \& R. C. Moran s.n. & No \\
\hline Indiana: Perry Co., $\mathrm{N}$ of Tell City* & C. H. Haufler s.n. & No \\
\hline Kansas: Douglas Co., Breidenthal Woods* & Windham 579 & Yes, 42II \\
\hline Kansas: Chautauqua Co., $\mathrm{W}$ of Elgin & R. E. Brooks 16162 & Yes, 42II \\
\hline Kansas: Miami Co., $\mathrm{S}$ of Homewood & C. H. Haufler s.n. & Yes, 42II \\
\hline Michigan: Washtenaw Co., Homer Woods & C. H. Haufler \& W. H. Wagner s.n. & Yes, 42II \\
\hline Missouri: Boone Co., SW of Columbia & R. E. Brooks 15298 & Yes, 42II \\
\hline Missouri: Cooper Co., Arrow Rock & R. E. Brooks \& C. H. Haufler 15343 & Yes, 42II \\
\hline Missouri: Franklin Co., Meramec State Park & R. E. Brooks \& C. H. Haufler 15341 & Yes, 42II \\
\hline Missouri: St. Louis Co., near Allenton* & R. E. Brooks \& C. H. Haufler 15332 & Yes, 42II \\
\hline North Carolina: Swain Co., Nantahala Gorge & W. H. Wagner s.n. & Yes, 42II \\
\hline \multicolumn{3}{|l|}{ C. tennesseensis } \\
\hline Illinois: Jackson Co., Fountain Bluff & C. H. Haufler \& R. C. Moran s.n. & Yes, 84II \\
\hline Kansas: Doniphan Co., $\mathrm{N}$ of Wathena & R. E. Brooks 14898 & Yes, 84II \\
\hline Missouri: Franklin Co., E of Sullivan & R. E. Brooks \& C. H. Haufler 15334 & Yes, 84II \\
\hline Missouri: LaClede Co., Big Niangua River & B. C. Phillips s.n. & Yes, 84II \\
\hline Nebraska: Richardson Co., NE of Shubert & R.E. Brooks 14925 & Yes, 84II \\
\hline Oklahoma: Ottawa Co., Dripping Springs & C. H. Haufler \& C. K. Teale s.n. & Yes, 84II \\
\hline \multicolumn{3}{|l|}{ C. tennesseensis $\times$ C. bulbifera } \\
\hline Missouri: Boone Co., SW of Columbia & R. E. Brooks \& C. H. Haufler 15302 & Yes, $42 \mathrm{II}+42 \mathrm{I}$ \\
\hline Nebraska: Richardson Co., NE of Shubert & R. E. Brooks $14925 a$ & Yes, $42 \mathrm{II}+42 \mathrm{I}$ \\
\hline \multicolumn{3}{|l|}{ C. tennesseensis $\times$ C. protrusa } \\
\hline Kansas: Chautauqua Co., $\mathrm{W}$ of Elgin & R. E. Brooks 16163 & Yes, $42 \mathrm{II}+42 \mathrm{I}$ \\
\hline Missouri: St. Louis Co., near Allenton & R. E. Brooks \& C. H. Haufler 15331 & Yes, $42 \mathrm{II}+42 \mathrm{I}$ \\
\hline
\end{tabular}

tures surveyed are listed in Table 3 and depicted in Figure 1. Because the species are often difficult to discern based solely on leaf features (often the only part preserved on herbarium specimens), we first used only quantitative leaf features to seek species-specific leaf attributes or combinations thereof. Involved in this analysis were 9 plants of C. bulbifera, 21 of $C$. protrusa, and 8 of $C$. tennesseensis. Because our first analysis could not completely discriminate the species (see Results), 
a second analysis was conducted that included qualitative characters (Table 3 ) as well as mean spore sizes per plant (Table 1). This second analysis included 8 plants of $C$. bulbifera, 14 of $C$. protrusa, and 4 of $C$. tennesseensis. The data from both sets were analyzed with the BMDP7M stepwise discriminant analysis program (BMDP Statistical Software, 1981, UC Press). For each step in the analyses we allowed an experiment-wise error rate of $\alpha=0.05$ and judged the significance of each approximate $F$-ratio as the criterion for entry of a variable into the discriminant models. The critical values of $F$ were estimated using Bonferroni's inequality (Ranker \& Schnabel, 1986).

Unlike angiosperms, the gametophyte generation of fern species is independent of the sporophyte. Whereas the sporophyte is important in maintaining long-term survival of individuals, the gametophyte carries out sexual reproduction and initial establishment of populations. Thus, in developing a complete picture of the biology of fern species as well as characterizing evolutionary tendencies, analyses of gametophyte reproductive biology are necessary. In a previous study Haufler \& Ranker (1985) determined which Cystopteris species produced and/or responded to antheridiogen. In the present study 100 gametophytes of each species were reared individually, employing the culture conditions described in Haufler \& Ranker (1985), and assayed for genetic load following the procedures outlined by Lloyd (1974).

Analyses of chromosomal behavior at meiosis were especially important in characterizing suspected hybrid individuals. The procedures followed in obtaining and photographically documenting stages in sporogenesis were described in Haufler et al. (1985). Voucher specimens for each chromosome count will be deposited at KANU.

Electrophoretic analyses of isozyme variability were performed as described by Haufler (1985). Leaf samples were ground in the phosphate grinding buffer of Soltis et al. (1983) using a mortar and pestle or by placing them in spot plate wells and using a round-bottomed centrifuge tube as a pestle. Each of the 22 enzymes listed in Soltis et al. (1983) was surveyed and was subjected to a variety of gel and electrode buffer conditions (largely those of Soltis et al., 1983). Enzymes that provided consistent, interpretable results were hexokinase (HK), isocitrate dehydrogenase (IDH), leucine amino peptidase (LAP), the more cathodal (presumably cytosolic - see Weeden, 1983) bands of phosphoglucoisomerase (PGI-2), two sets of bands (presumably representing cytosolic and chloroplastic enzymes - see Weeden, 1983) for phosphoglu-
TABLE 3. List of features included in morphometric analysis. Asterisks indicate those illustrated in Figure 1. Plus marks indicate features that were statistically significant in discriminating species.

\footnotetext{
1-5. FEATURES OF ENTIRE LEAF

* 1 . Length of petiole $(\mathrm{cm})$

$* 2$. Length of blade $(\mathrm{cm})$

*3. Angle of departure of median pinna

*4. Length of rachis between lowest pinna of first pinna pair and lowest pinna of second pinna pair $(\mathrm{mm})$

*5. Length of rachis between lowest pinna of second pinna pair and lowest pinna of third pinna pair (mm)
}

6-17. FEATURES OF LONGEST PINNA

6. Number of pinna pairs from base (first one $=$ number l)

*7. Length of pinna stalk (petiolule) $(\mathrm{mm})$

*8. Length of pinna $(\mathrm{mm})$

*9. Width of pinna $(\mathrm{mm})$

$+^{*} 10$. Number of segments along acroscopic edge of pinna (including pinnatifid ones)

*11. Length of first acroscopic pinnule (mm)

*12. Number of major sinuses along distal edge of first acroscopic pinnule

*13. Length of stalk of basiscopic pinnule (mm)

*14. Length of pinna rachis between lowest two pinnule pairs (mm)

*15. Angle formed by apex of pinna

${ }^{*}$ 16. Angle formed by basiscopic pinnule axis with pinna axis

*17. Angle of proximal portion of basiscopic pinnule base with pinnule axis

18-20. QUalitative FEATURES

18. Presence or absence of bulblets

+19 . Presence or absence of glandular trichomes

20. Color of petiole

+21 . Spore size (see Table 1)

comutase (PGM-I, the more anodal set, and PGM2 , the more cathodal set), shikimate dehydrogenase (SkDH), and two sets of bands (presumably representing cytosolic and chloroplastic enzymes - see Weeden, 1983) for triosephosphate isomerase (TPI1 , the more anodal set, and TPI-2, the more cathodal set). HK, PGI-2, LAP, TPI-1, and TPI-2 showed the best resolution on either system 6 of Soltis et al. (1983) or the modified system 8 discussed in Haufler (1985). IDH, PGM-1, PGM-2, and $\mathrm{SkDH}$ were resolved best on the modified system 11 of Soltis et al. (1983) discussed in Haufler (1985). Identification of bands shared among populations and species was accomplished through coelectrophoresis of the samples on the same gel.

Individual gametophytic progeny were used to assess the genetics of sporophytic banding patterns. We followed the electrophoretic procedures de- 

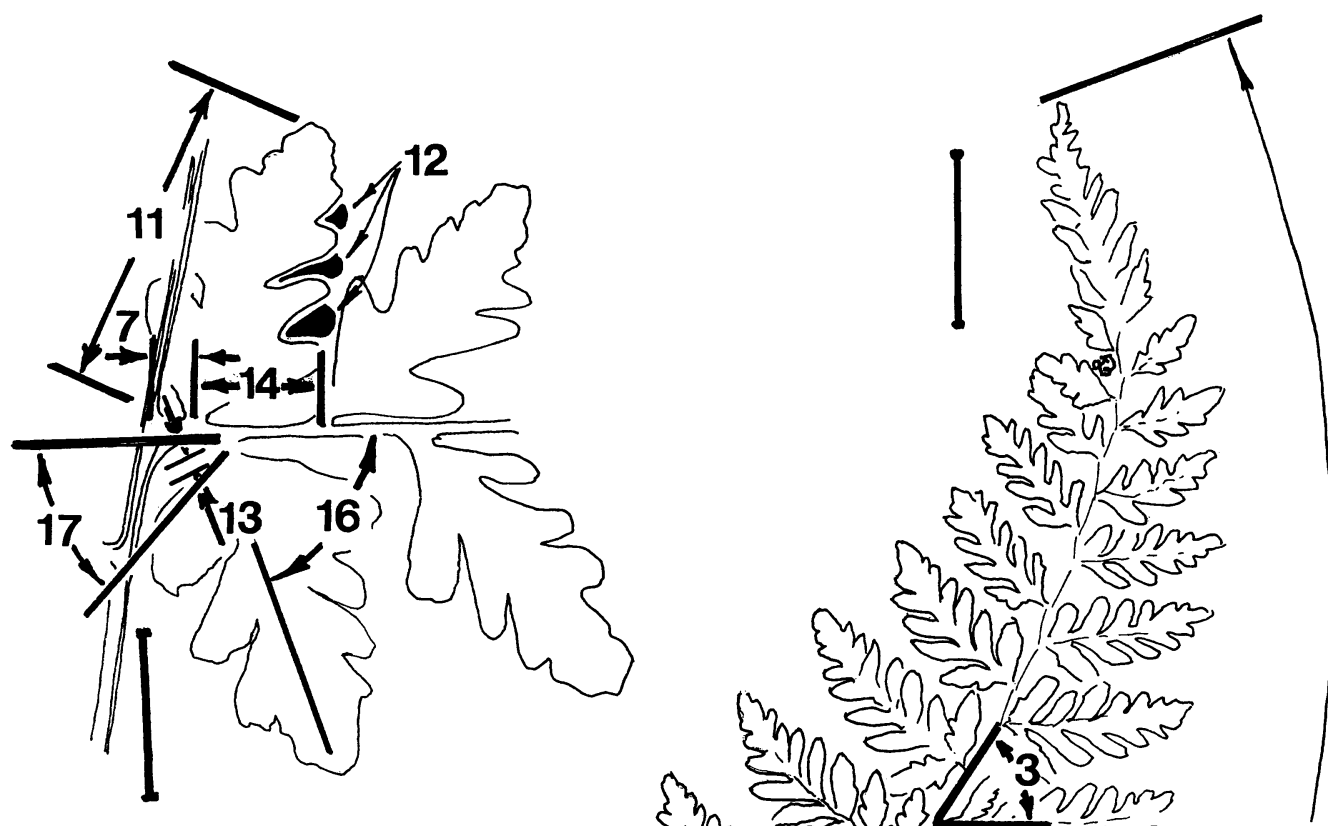

है/ है?

s, ed
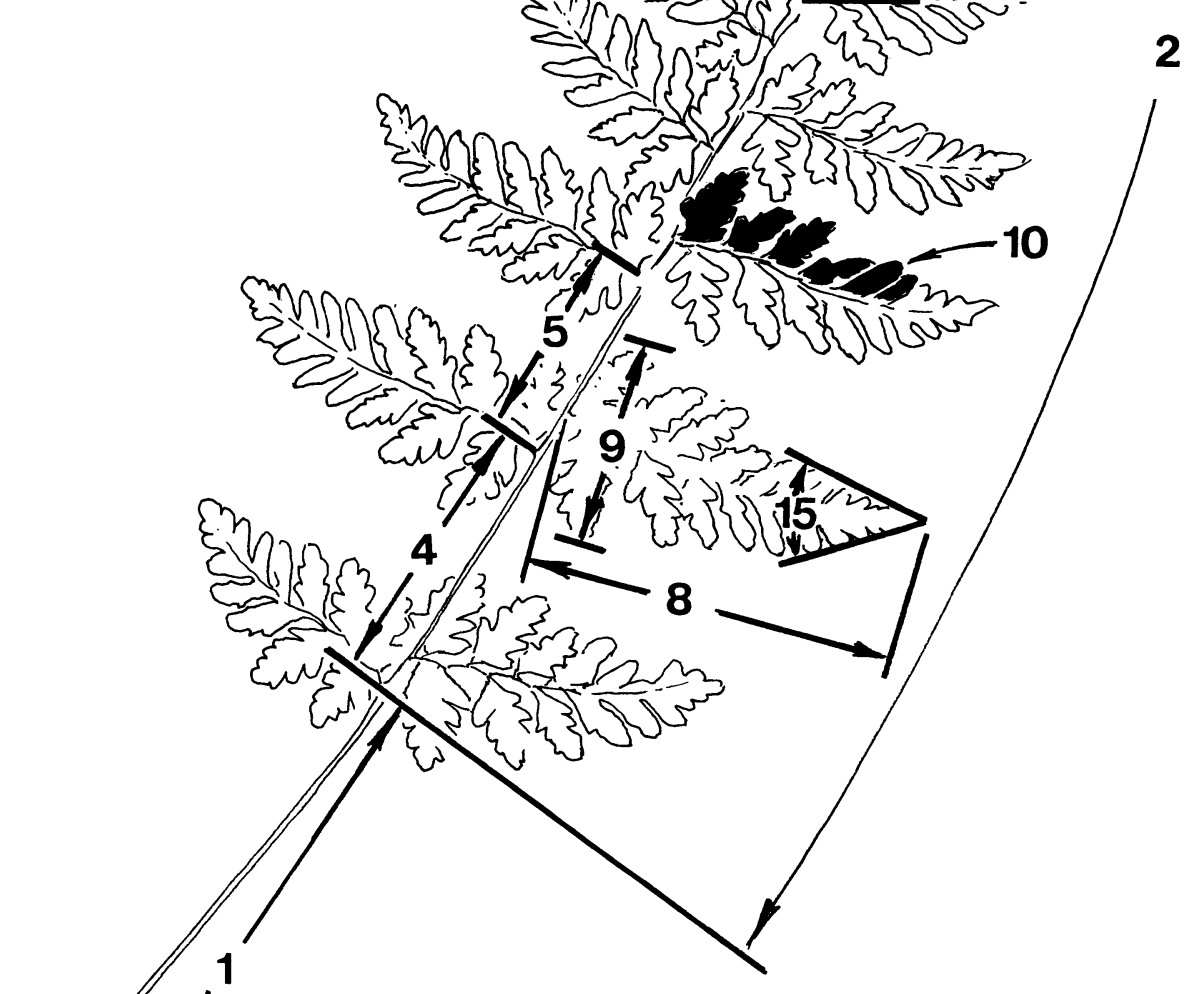
scribed by Gastony \& Gottlieb (1982) as modified by Haufler \& Soltis (1984). For the enzymes surveyed, gametophytes express the same isozymes as do sporophytes. Because gametophytes are multicellular, haploid individuals derived from single meiotic products (spores), gametophytic progeny arrays from single sporophytes can be used to determine directly the genetic constitution of complex sporophytic banding patterns. In this way, segregational analyses of putatively heterozygous banding patterns can be performed without pursuing more time-consuming crossing programs.

After allelic determinations were made for each of the nine putative loci, allozymic data from a set of representative populations (Table 4) were analyzed. The proportion of polymorphic loci $(\mathrm{P})$ and the mean number of alleles per locus (A) were calculated from these populational data. A statistical program (LYNSPROG) written by Marilyn Loveless, The College of Wooster, Wooster, Ohio, was used to calculate levels of heterozygosity, the fixation index $(F)$, and Nei's coefficients of genetic identity and distance. Because $C$. protrusa tends to be clonal, separate calculations were made for populations consisting of ( 1 ) each leaf sampled (ramets) and (2) only the number of different genotypes (genets). The first should overestimate the number of individual organisms while the second should underestimate it.

\section{RESUlTS}

SPORES.

Blasdell (1963) and Moran (1982) noted the value of spore features for identifying hybrids and in determining the ploidy of specimens. Despite Lovis's (1977) caveat that it may not be appropriate in Cystopteris to infer ploidy levels from spore measurements, we were able to verify independently through analyses of meiotic chromosome behavior that spore size did correlate with several critical genetic features of species (Table 1). We agree with Lovis that spore size comparisons alone do not substitute for direct chromosome analyses, but once a strong correlation between spore features and genetic condition is established, spores can be extremely valuable in surveying specimens rapidly. Each species differed significantly in mean spore size from the other two (pairwise $t$-tests, $P$ $<0.002$ ). Although $C$. bulbifera spores were larg-

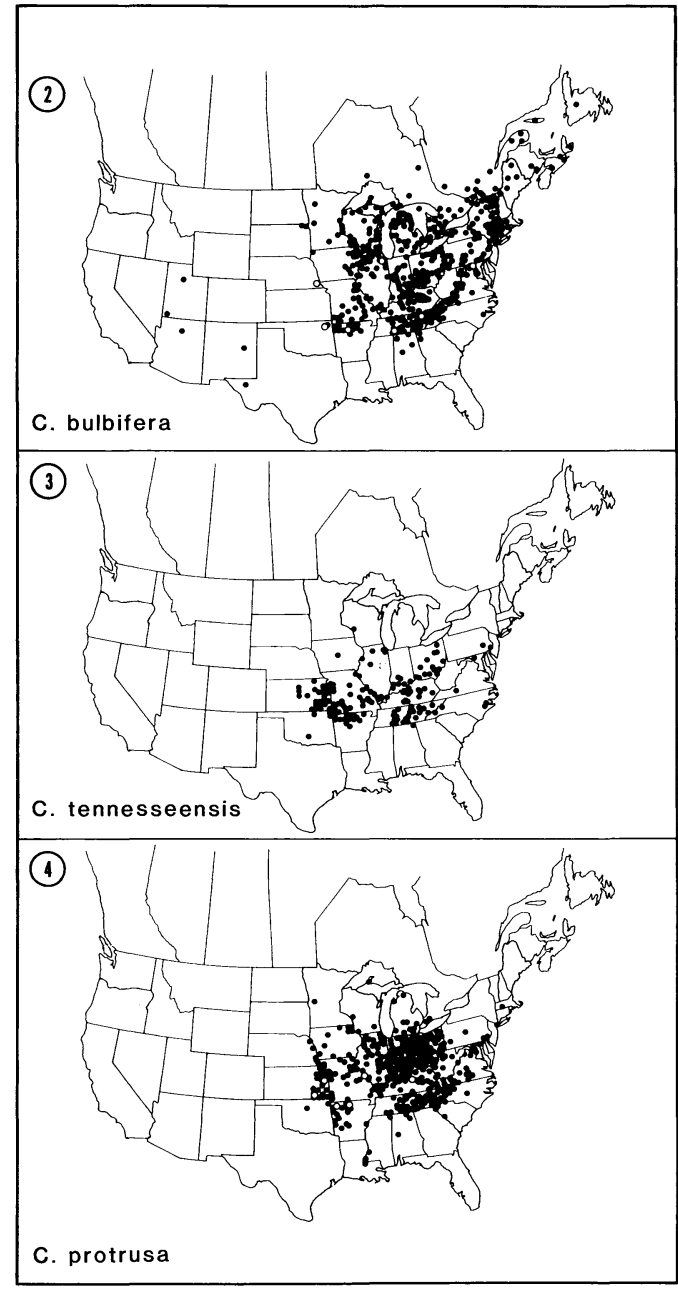

Figures 2-4. Geographic distributions of members of the Cystopteris tennesseensis complex based on data from herbarium specimens. Dots indicate counties where specimens were collected.-2. C. bulbifera. -3 . C. tennesseensis. -4. C. protrusa. Open circles on Figures 2 and 4 show locations of putative triploid backcross hybrids.

er than those of $C$. protrusa, spores of tetraploid C. tennesseensis showed the further size increase commonly associated with higher ploidy.

\section{MORPHOLOGICAL ANALYSES OF SPOROPHYTES}

The taxa in the Cystopteris tennesseensis complex are among the most distinctive in the genus. There are more unique features that characterize

FIGURE 1. Leaf features included in morphometric analysis. Numbers correspond to descriptions of features in Table 3. Scale bars: for whole leaf $=2.0 \mathrm{~cm}$; for pinna base $=0.5 \mathrm{~cm}$. 
each species than there are in any other group of Cystopteris species. Cystopteris protrusa, for example, has long internodes and a peculiar, protruding rhizome apex whose growing point extends past the current season's leaves. Given the evidently rapid growth of the rhizome, we were not surprised to find extensive clones of this species in mature woodlands. Cystopteris bulbifera, commonly found on moist cliffs, has short internodes and bears asexual reproductive bulblets on its leaves, and most individuals have tack-shaped, glandular trichomes that are particularly prominent on the indusia and along the rachis between pinnae. The allotetraploid $C$. tennesseensis combines the genomes of its progenitor diploids and, perhaps as a result of this genetic amalgamation, is morphologically variable. In many features, the tetraploid is intermediate between the diploids, e.g., it has poorly formed bulblets and a reduced frequency of glandular trichomes. Its rhizome features, however, are not intermediate. Perhaps because it inhabits somewhat disturbed, often dry cliffs rather than forest floors, it has the short internodes typical of C. bulbifera.

Even though past workers (Shaver, 1954; Blasdell, 1963) provided well constructed species descriptions and indicated the distinctive features of each species, taxonomists not familiar with the genus continue to encounter problems when identifying members of the $C$. tennesseensis complex. To generate additional discriminating features and in trying to separate environmentally induced variability from that based on genetic differences, we performed a discriminant analysis of leaf morphology on plants grown in a common garden. In the first analysis, employing only quantitative leaf characters, only two features were entered into the model as being statistically significant, the number of acroscopic segments on the longest pinna (\#10, Table 3, Fig. 1) and the angle formed by the basiscopic pinnule axis with the pinna axis (\#16). The species differed significantly from one another in the space defined by the two canonical axes $(P$ $<0.01)$. The first axis accounted for $85 \%$ of the total variance and separated $C$. bulbifera from the other two species. The two variables in the model exhibited similar character loadings (standardized coefficients) on the first axis, 0.608 for \#10 and 0.720 for \#16, indicating a nearly equal contribution to the canonical variable. Inspection of the original data revealed that $C$. bulbifera is distinguished from the other species by a larger number of acroscopic segments on the longest pinna and a larger angle formed by the basiscopic pinnule. The second axis accounted for the remaining $15 \%$ of the variance. The jackknifed classification matrix correctly identified $100 \%$ of the C. bulbifera individuals, $71.4 \%$ of $C$. protrusa, and $87.5 \%$ of C. tennesseensis. Six individuals of $C$. protrusa were incorrectly identified as $C$. tennesseensis, and one individual of $C$. tennesseensis was incorrectly identified as $C$. protrusa.

A second discriminant analysis was conducted in which qualitative leaf features (listed in Table 3 ) and spore size were added to the data set in an attempt to identify combinations of characters that would allow a better discrimination of species than was obtained in the first analysis. In this second analysis, three characters were entered into the model as statistically significant: angle of the basiscopic pinnule (\#16), presence or absence of glandular trichomes, and mean spore size (Table 1). The first canonical axis accounted for $82 \%$ of the total variance, and the character loadings were 0.809 (\#16), 0.875 (glandular trichomes), and 0.485 (spore size). The first axis primarily separated the two diploids from one another. As indicated by the relative value of the loadings, the diploids were primarily distinguished by the angle of the basiscopic pinnule and the presence or absence of glandular trichomes. On the second axis, the character loadings were -0.081 (\#16), 0.429 (glandular trichomes), and -0.887 (spore size). The large spore size of the tetraploid, therefore, was the most important factor in discriminating it from the diploids. The jackknifed classification matrix produced $100 \%$ correct classifications for all individuals in the analysis.

\section{BIOGEOGRAPHY}

The distribution of species is shown in Figures 2-4. Cystopteris bulbifera is the most northern species, extending well into Canada. Cystopteris protrusa is most common in the east-central United States and is rare in southern Canada (Britton et al., 1984; Haufler et al., 1985). The allotetraploid derivative $C$. tennesseensis is found primarily in the region of overlap of the two diploids. Using spore abortion as an indicator of sterility, we identified interspecific hybrids between the tetraploid and its diploid parents. The locations of these hybrids are indicated as open circles on Figures 2 and 4 . Because the morphological features are quite plastic, it is not always possible to determine which of the diploids hybridized with $C$. tennesseensis in forming the sterile plants. Using chromosomal and isozymic data, we were able to document that backcrosses to both parents do occur in nature (see below). 

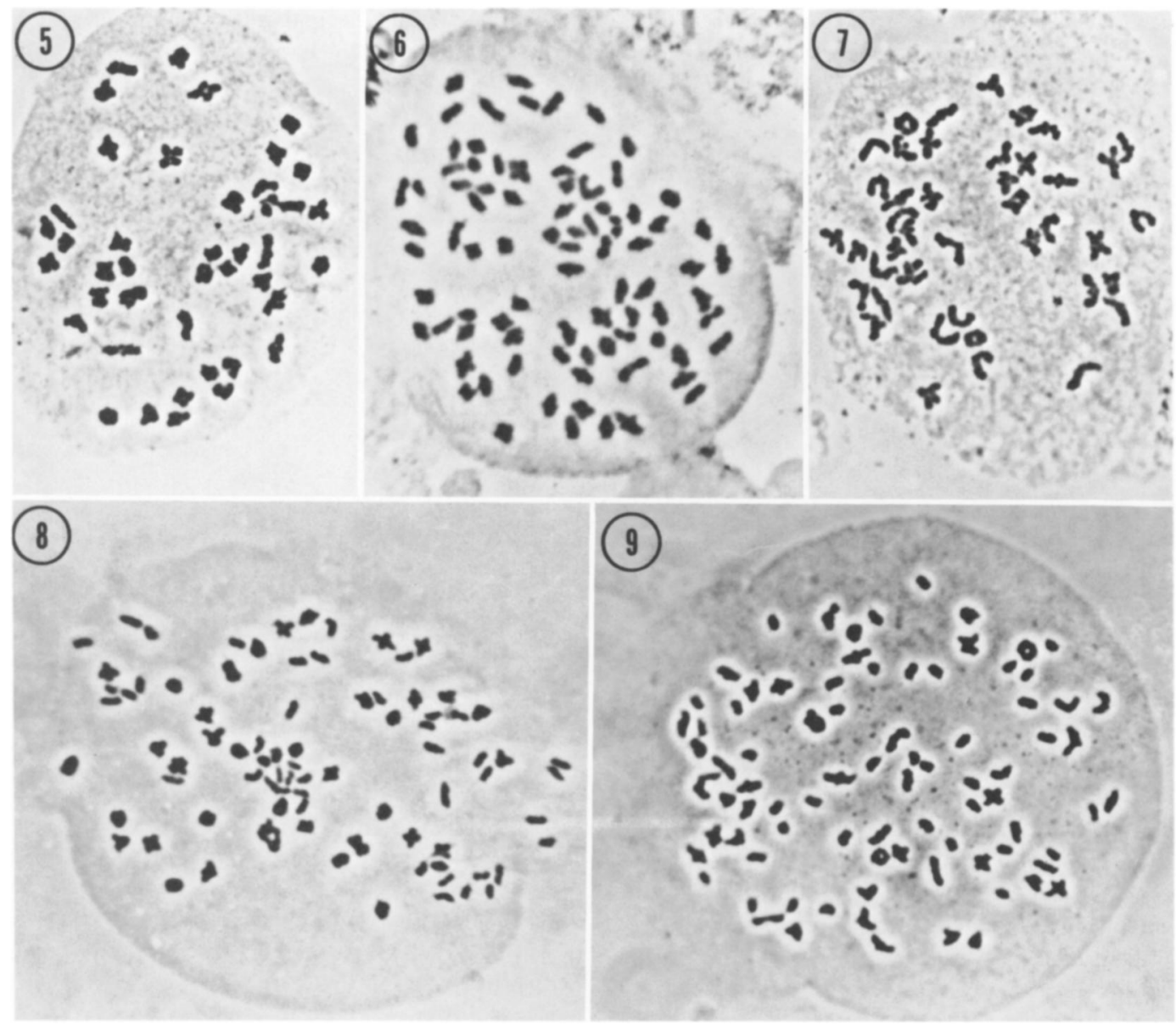

FigURES 5-9. Representative meiotic chromosome squashes. - 5. C. bulbifera, $n=42 \mathrm{II} .-6$. C. tennesseensis, $n=84 \mathrm{II} .-7$. C. protrusa, $n=42 \mathrm{II}$. 8, 9. Backcross hybrids between $C$. tennesseensis and its diploid progenitors. Identification of hybrids was based on morphological and isozymic data. -8 . Hybrid between $C$. tennesseensis and C. bulbifera, $n=42 \mathrm{II}+42 \mathrm{I}$. -9 . Hybrid between $C$. tennesseensis and $C$. protrusa, $n=42 \mathrm{II}+42 \mathrm{I}$. All $\times$ 1,000 .

\section{GAMETOPHYTES}

Summarizing previous studies of Cystopteris gametophytes (Blasdell, 1963; Profumo, 1969; Auquière \& Moens, 1972), Blasdell (1963, p. 6) stated, "All of the taxa examined are similar in the bulk of their gametophytic features." Our study of gametophyte ontogeny confirmed Blasdell's assessment of the level of morphological variability. However, Haufler \& Ranker (1985) demonstrated significant interspecific variation in response to the pheromone antheridiogen.

Genetic load studies have been used to look into aspects of reproductive biology (Lloyd, 1974). Because inbreeding brings about the expression of recessive alleles, species with low genetic load should be more inbred, whereas those having high genetic load are presumed to be outcrossers. In homosporous ferns, levels of genetic load can be determined by assessing the ability of isolated gametophytes to produce sporophytes. In the present study, none of the 100 isolated gametophytes of $C$. bulbifera and $C$. protrusa produced sporophytes, even after repeated waterings over a four-month period. However, 25 of the 100 isolated gametophytes of C. tennesseensis did form sporophytes. Although we did not examine each isolated gametophyte, we have verified that gametophytes of the diploid species do become hermaphroditic in culture. Thus, genetic load in the tetraploid is significantly lower than that in the diploids $(3 \times 2$ contingency table of species vs. sporophyte production: $G=59.63$, $P<0.001)$. 


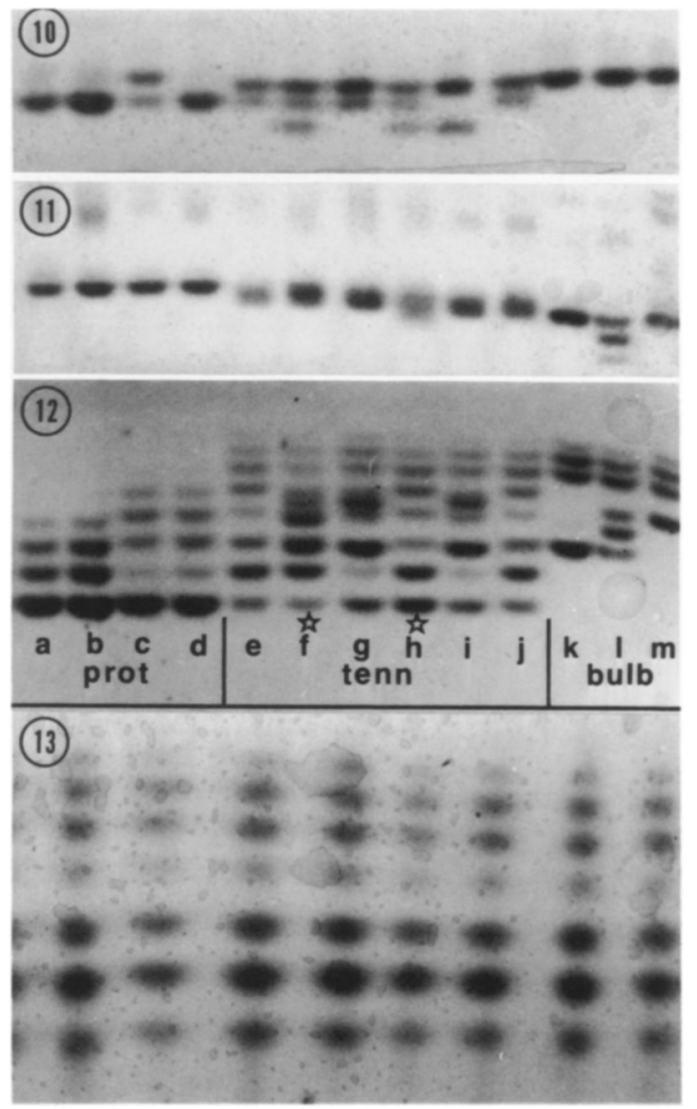

Figures 10-13. Representative isozyme profiles. Anode $=$ top of photographs, cathode $=$ bottom of photographs. 10-12. Interspecific comparisons of banding patterns. Lanes a-d $=C$. protrusa; $\mathrm{e}^{-\mathrm{j}}=C$. tennesseensis; $\mathrm{k}-\mathrm{m}=C$. bulbifera. Lanes $\mathrm{f}$ and $\mathrm{h}$ (starred) are from triploid backcross hybrids between $C$. tennesseensis and $C$. protrusa. - 10. SkDH (monomeric, single compartment). Compare lanes $\mathrm{i}$ and $\mathrm{j}$ where the upper band of these fixed heterozygotes are from $C$. bulbifera and the lower bands are from $C$. protrusa. Differences in the $C$. protrusa contribution may have resulted from recurring origin of the tetraploid. Note that the backcross hybrids contain both $C$. protrusa bands. - $1 \mathrm{l}$. PGI (dimeric; anodal, presumably chloroplastic bands are not well resolved and were not scored; cathodal bands are presumably cytoplasmic). Because the $C$. bulbifera and $C$. protrusa bands have very similar mobilities, the fixed heterozygous pattern in $C$. tennesseensis appears as a broad fuzzy band consisting of the parental bands and an interlocus heterodimeric band. - 12. TPI (dimeric; in both diploids, anodal, multiple-banded pattern probably rep-. resents a post-translational modification of the enzyme (see discussion in Gastony, 1988, and Hickey et al., 1989)); cathodal bands show typical dimeric enzyme expression in homozygotes and heterozygotes (compare lanes $\mathrm{k}-\mathrm{m}$ ); in tetraploids, anodal and cathodal bands overlap. Lanes $a$ and $b$ vs. lanes $c$ and $d$ show differing mobilities for the multiple-banded enzymes. Lanes $i$ and $j$ probably are from plants that had different $C$. bulbifera parents. Lane i received the more anodal band from $C$. bulbifera while lane $\mathrm{j}$ received the more cathodal band. -13 . TPI expres-

\section{MEIOTIC CHROMOSOME BEHAVIOR}

Analyses of meiosis from plants collected across the species ranges generated consistent counts of $n=42$ in $C$. bulbifera (Fig. 5) and C. protrusa (Fig. 7), and $n=84$ in C. tennesseensis (Fig. 6). Table 2 lists the collection localities of the plants yielding new chromosome counts. In addition to analysis of the sexual species, plants verified via isozyme analysis to be backcross hybrids were also studied cytogenetically. As shown in Figures 8 and 9, all hybrids showed a complement of 42 bivalents plus 42 univalents expected from backcross hybrids of an allotetraploid to its diploid progenitors. These results indicate little or no chromosomal homology between the diploid species $C$. protrusa and $C$. bulbifera and suggest that $C$. tennesseensis contains one genome of each.

\section{ISOZYMES}

Isozyme patterns of the tetraploid $C$. tennesseensis are perfectly additive of those from the two diploid species. Gametophytic progeny arrays demonstrated that the complex banding patterns did not segregate during meiosis (Fig. 13), suggesting that the isozymes comprising these patterns were coded by genes situated on nonhomologous chromosomes contributed by the two diploid parents. Given that all tetraploids showed fixed heterozygosity that always combined patterns from each diploid progenitor, no evidence of "orphan alleles" or gene silencing could be detected. All isozymic variability observed in the allotetraploid apparently resulted from the incorporation of various diploid allozymes into the polyploid derivative via recurring allopolyploid events (Figs. 10-12, and see Haufler \& Soltis, 1986).

Combining chromosomal and isozymic data made it possible to identify hybrids and determine their parentage. Sporogenesis was studied in plants having aborted spores. Such plants were shown to be triploids having 42 pairs and 4.2 univalents during meiosis and thus were determined as backcrosses between $C$. tennesseensis and either $C$. protrusa or $C$. bulbifera. Even though the variability of morphological features could preclude precise identification of parents, the triploids always contained unequal enzyme contributions from the two parents. Thus, dosage effects could be used to show

sion in individual gametophytic progeny of a sporophyte having the banding pattern seen in lanes $e$ and $j$ of Figure 12. There is no segregation for the complex pattern, indicating that the sporophyte was a fixed heterozygote. 
TABLE 4. Locations and sizes ( $n$ ) of populations of diploid Cystopteris species surveyed in generating genetics statistics (see Tables 5-7).

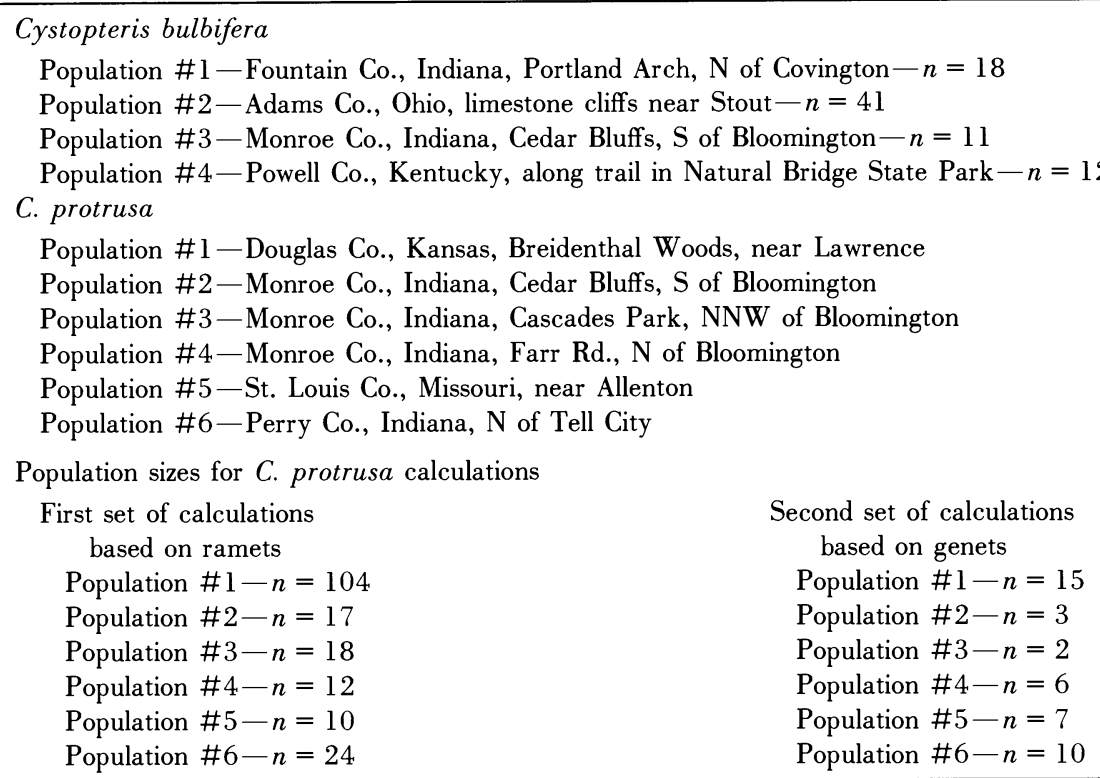

which backcross had formed the hybrids. Hybrids formed between $C$. tennesseensis and C. protrusa had the $C$. protrusa bands stained more intensely than the C. bulbifera contribution (Figs. 10-12, lanes $\mathrm{f}$ and $\mathrm{h}$ ). Conversely, C. tennesseensis $\times C$. bulbifera hybrids contained a double dose of $C$. bulbifera.

Although all nine enzymes helped corroborate that $C$. tennesseensis was an amalgam of its progenitor diploids, the most complex and informative enzyme was TPI (Fig. 12). For both diploids, banding patterns indicative of two genetic loci were resolved. The cathodal bands showed banding patterns typical of dimeric enzymes (single-banded in homozygotes and three-banded in heterozygotes). The anodal zone of bands were expressed as fixed, multiple-banded patterns which probably represent post-translational modifications (Gastony, 1988; Hickey et al., 1989). In C. protrusa (lanes a-d), the strongly staining, most cathodal band was an invariant marker for the species. The more weakly staining, multiple-band pattern was variable. As shown in Haufler \& Soltis (1986), three patterns were detected among the sporophytes surveyed: a slow-migrating triplet (as in lanes $a$ and $b$ of the present paper), a fast-migrating triplet (not illustrated here, but see Haufler \& Soltis (1986, fig. la)), and the complex, five-banded heterozygote between them (as in lanes $\mathrm{c}$ and d). In C. bulbifera (lanes $\mathrm{k}-\mathrm{m}$ ), the rapidly migrating triplet pattern was invariant while there were two alleles expressed for the cathodal locus. Lane $l$ is the heterozygote formed from outcrossing between homozygotes such as $\mathbf{k}$ and $\mathrm{m}$. When these diploid variants are combined in $C$. tennesseensis (lanes $\mathrm{e}-\mathrm{j}$ ), some remarkably complex patterns result. Lanes e and $j$ appear to be relatively simple additive patterns between plants such as those in lanes a $(C$. protrusa) and $\mathrm{k}($ C. bulbifera). Lanes $\mathrm{g}$ and $\mathrm{i}$ combine the bands found in lanes a and $\mathrm{m}$. Lane $\mathrm{f}$ (identified via morphology and meiotic chromosomal behavior as a triploid backcross between $C$. protrusa and C. tennesseensis) combines one dose of a profile like lane $\mathrm{m}$ with two doses of lane b. Lane $\mathrm{h}$ (also a $C$. protrusa $\times$ C. tennesseensis triploid) appears to combine one dose of a plant like lane $\mathrm{k}$ with two doses of one like lane b or c. Note also the banding patterns for the triploids in $\mathrm{SkDH}$ (Fig. 10). For lanes $\mathrm{f}$ and $\mathrm{h}$, the two cathodal bands are shared with $C$. protrusa while only the most anodal band is found in $C$. bulbifera. These $\mathrm{SkDH}$ patterns help confirm that both triploids contain two genomes from $C$. protrusa and only one from $C$. bulbifera. The slowest migrating SkDH band in $C$. tennesseensis (lanes $\mathrm{f}, \mathrm{h}$, and $\mathrm{i}$ ) is from $C$. protrusa even though it is not seen in the representative $C$. protrusa plants on this gel. The rapidly migrating $\mathrm{SkDH}$ band in lane $\mathrm{c}$ is a rare $C$. protrusa variant 
TABLE 5. Population genetics statistics. $\mathrm{P}=$ proportion polymorphic loci, $\mathrm{A}=$ average number of alleles per locus. $\mathrm{P}$ and $\mathrm{A}$ were identical for the ramet and genet samples of C. protrusa.

\begin{tabular}{|c|c|c|c|c|c|c|}
\hline \multicolumn{7}{|c|}{ Cystopteris bulbifera } \\
\hline \multirow{2}{*}{$\begin{array}{c}\text { Popu- } \\
\text { lation } \\
\text { num- } \\
\text { ber }\end{array}$} & \multirow{2}{*}{\multicolumn{2}{|c|}{$\mathrm{P}$}} & \multirow[b]{2}{*}{ A } & \multicolumn{3}{|c|}{$\begin{array}{c}\text { Mean } \\
\text { heterozygosity }\end{array}$} \\
\hline & & & & $\begin{array}{c}\text { Ob- } \\
\text { served }\end{array}$ & \multicolumn{2}{|c|}{$\begin{array}{c}\text { Ex- } \\
\text { pected }\end{array}$} \\
\hline 1 & \multicolumn{2}{|c|}{0.67} & 1.89 & 0.435 & \multicolumn{2}{|c|}{0.470} \\
\hline 2 & \multicolumn{2}{|c|}{0.56} & 1.78 & 0.138 & \multicolumn{2}{|c|}{0.219} \\
\hline 3 & \multicolumn{2}{|c|}{0.56} & 1.78 & 0.394 & \multicolumn{2}{|c|}{0.334} \\
\hline 4 & \multicolumn{2}{|c|}{0.67} & 1.78 & 0.347 & \multicolumn{2}{|c|}{0.273} \\
\hline Mean & \multicolumn{2}{|c|}{0.62} & 1.81 & 0.329 & \multicolumn{2}{|c|}{0.324} \\
\hline \multicolumn{7}{|c|}{ Cystopteris protrusa } \\
\hline \multirow{2}{*}{$\begin{array}{l}\text { Popu- } \\
\text { lation } \\
\text { num- } \\
\text { ber }\end{array}$} & \multirow[b]{2}{*}{$\mathrm{P}$} & \multirow[b]{2}{*}{ A } & \multicolumn{2}{|c|}{$\begin{array}{l}\text { Mean } \\
\text { heterozygosity } \\
\text { for ramets }\end{array}$} & \multicolumn{2}{|c|}{$\begin{array}{c}\text { Mean } \\
\text { heterozygosity } \\
\text { for genets }\end{array}$} \\
\hline & & & $\begin{array}{c}\mathrm{Ob}- \\
\text { served }\end{array}$ & $\begin{array}{c}\text { Ex- } \\
\text { pected }\end{array}$ & $\begin{array}{c}\mathrm{Ob}- \\
\text { served }\end{array}$ & $\begin{array}{c}\text { Ex- } \\
\text { pected }\end{array}$ \\
\hline 1 & 0.56 & 1.67 & 0.128 & 0.153 & 0.152 & 0.223 \\
\hline 2 & 0.22 & 1.22 & 0.042 & 0.104 & 0.048 & 0.134 \\
\hline 3 & 0.56 & 1.56 & 0.524 & 0.302 & 0.429 & 0.286 \\
\hline 4 & 0.78 & 1.88 & 0.357 & 0.342 & 0.286 & 0.345 \\
\hline 5 & 0.56 & 1.67 & 0.157 & 0.235 & 0.204 & 0.273 \\
\hline 6 & 0.44 & 1.56 & 0.185 & 0.176 & 0.200 & 0.198 \\
\hline Mean & 0.52 & 1.59 & 0.232 & 0.219 & 0.220 & 0.243 \\
\hline
\end{tabular}

not incorporated in any of the $C$. tennesseensis plants shown here.

A series of populations was surveyed (Table 4) and used to generate calculations of $\mathrm{P}, \mathrm{A}$, and levels of heterozygosity (Table 5), Nei's coefficients of genetic identity and distance (Table 6), and the fixation index $(F)$ (Table 7$)$. Results derived from ramet and genet views of individuality in populations of $C$. protrusa did not differ markedly. Observed heterozygosity differed by 0.012 and mean genetic identities were within 0.013 of each other. Although the calculations of $F$ derived from the ramet samples appear to have a large number of significant departures from random mating, these values are both positive and negative. A mean of -0.0687 for these significant values suggests that the ramet figures may be influenced by oversampling of certain clonal genotypes. Cystopteris bulbifera and $C$. protrusa shared no alleles at the loci examined; thus, based on nine putative loci (most of which code for "conservative" enzymes (Gillespie \& Kojima, 1968)), the genetic identity between these congeneric species was zero.

\section{Discussion}

\section{BIOGEOGRAPHY AND ECOLOGY}

Fieldwork and mapping of species distributions provided new perspectives on the biology and evolution of the Cystopteris tennesseensis species complex. Often two and occasionally all three species were sympatric. In such situations, $C$. protrusa was confined to the forest floor, $C$. bulbifera was on moist cliffs and among the talus at the base of cliffs, and $C$. tennesseensis could be found on drier cliffs and/or disturbed sites such as old rock walls. When plants of $C$. protrusa and $C$. bulbifera were intermingled, a special effort was made to locate the primary diploid hybrid between them. However, primary hybrids could not be found. Others have noted that primary hybrids of well established allopolyploids can rarely be discovered (e.g., the Appalachian Asplenium complex (Wagner, 1954; Werth et al., 1985a) and the Dryopteris carthusiana complex (Wagner, 1971)). Perhaps in these situations, the intermediate niche necessary for establishment of a diploid hybrid is occupied by the allopolyploid species.

In contrast to the primary diploid hybrid situation, when $C$. tennesseensis was sympatric with either parent, triploid backcross hybrids could be identified. Although an equivalent number of stations having putative hybrids has been identified (Figs. 2, 4), fieldwork demonstrated that at any one locality, hybrids with $C$. protrusa were more frequent than those involving C. bulbifera. This result may reflect the greater specificity of gametophytic safe sites for the latter species. Alternatively, differences in hybrid frequencies could be related to variation in response to antheridiogen. Haufler \& Ranker (1985) showed that $C$. protrusa responded to antheridiogen while $C$. bulbifera did not, and that $C$. tennesseensis had a reduced sensitivity to this antheridia-inducing pheromone. Under these circumstances, it is likely that crosses involving C. protrusa would be more frequent. In a given safe site containing spores of $C$. protrusa and $C$. tennesseensis, it is likely that $C$. tennesseensis gametophytes would be mostly female while neighboring $C$. protrusa gametophytes would be primarily male. If this scenario is accurate, one would predict that $C$. protrusa should be the male parent in most crosses.

Extending this argument to the origin of $C$. tennesseensis, it may be predicted that $C$. bulbifera would be the egg parent in most cases. This hypothesis could be tested using information from chloroplast DNA (cpDNA) sequence variability. 
TABLE 6. Population genetics statistics. Calculation of Nei's genetic identity and distance between infraspecific populations. Identity measures above the diagonal, distance measures below the diagonal.

\begin{tabular}{ccccc}
\hline \hline $\begin{array}{l}\text { Cystopteris bulbifera } \\
\begin{array}{l}\text { Population } \\
\text { number }\end{array}\end{array}$ & 1 & 2 & 3 & 4 \\
\hline 1 & - & 0.7356 & 0.7716 & 0.8103 \\
2 & 0.3071 & - & 0.9203 & 0.8734 \\
3 & 0.2592 & 0.0830 & - & 0.8474 \\
4 & 0.2104 & 0.1353 & 0.1656 & - \\
\multicolumn{7}{l}{ Mean genetic identity $=0.8264$} & & & \\
\hline
\end{tabular}

\begin{tabular}{|c|c|c|c|c|c|c|}
\hline \multicolumn{7}{|c|}{ Cystopteris protrusa-RAMET POPULATIONS } \\
\hline $\begin{array}{l}\text { Population } \\
\text { number }\end{array}$ & l & 2 & 3 & 4 & 5 & 6 \\
\hline 1 & - & 0.9857 & 0.9161 & 0.8518 & 0.8940 & 0.7917 \\
\hline 2 & 0.0144 & - & 0.9219 & 0.8313 & 0.9191 & 0.7937 \\
\hline 3 & 0.0876 & 0.0813 & - & 0.8578 & 0.8475 & 0.7599 \\
\hline 4 & 0.1604 & 0.1848 & 0.1534 & - & 0.7791 & 0.8271 \\
\hline 5 & 0.1120 & 0.0844 & 0.1655 & 0.2496 & - & 0.7280 \\
\hline 6 & 0.2336 & 0.2310 & 0.2745 & 0.1898 & 0.3174 & - \\
\hline \multicolumn{7}{|c|}{ Mean genetic identity $=0.8470$} \\
\hline \multicolumn{7}{|c|}{ Cystopteris protrusa-GENET POPULATIONS } \\
\hline $\begin{array}{l}\text { Population } \\
\text { number }\end{array}$ & 1 & 2 & 3 & 4 & 5 & 6 \\
\hline 1 & - & 0.9280 & 0.9449 & 0.8253 & 0.8769 & 0.7670 \\
\hline 2 & 0.0747 & - & 0.9275 & 0.7534 & 0.9364 & 0.7708 \\
\hline 3 & 0.0567 & 0.0753 & - & 0.8840 & 0.8674 & 0.7765 \\
\hline 4 & 0.1920 & 0.2832 & 0.1233 & - & 0.7285 & 0.7886 \\
\hline 5 & 0.1313 & 0.0657 & 0.1423 & 0.3167 & - & 0.7371 \\
\hline 6 & 0.2652 & 0.2603 & 0.2530 & 0.2375 & 0.3050 & - \\
\hline \multicolumn{7}{|c|}{ Mean genetic identity $=0.8342$} \\
\hline
\end{tabular}

Recent analyses (Stein \& Barrington, 1990) indicated that cpDNA is inherited uniparentally in ferns (but see Andersson-Kottö, 1930). If cpDNA is carried in the egg, most $C$. tennesseensis plants should contain the chloroplast genome of $C$. bulbifera.

The available data indicate that $C$. tennesseensis is a relatively young species. The range of the derived allotetraploid $C$. tennesseensis extends only slightly beyond that of its diploid progenitors (Figs. 2-4). Further, C. tennesseensis shows no evidence of gene silencing. For the enzymes surveyed, all plants displayed fixed heterozygotic banding patterns that were additive for bands found in the diploid progenitors. All variability in the tetraploid could be attributed to recurring hybridization between genetically different diploid ancestors. All of these features are those anticipated for allopolyploids having recent origins (Haufler \& Werth, 1986).

\section{GENETICS}

The mean levels of polymorphism and allelic variability for $C$. protrusa and $C$. bulbifera (Table $5)$ are similar to those expected of long-lived perennials $(P=0.66, A=2.07)$ having a primarily outcrossed breeding system $(\mathrm{P}=0.51, \mathrm{~A}=1.85)$ (Hamrick et al., 1979). Based on calculations of mean observed and expected heterozygosity values (Table 5), neither diploid species appears to have an excess or deficiency of heterozygosity relative to Hardy-Weinberg expectations. The mean genetic identity among populations (Table 6: 0.8359) is at the lower end of that found among other fern species $(I=0.912$, range $=0.78-0.99$ in Soltis \& Soltis, 1989). Table 7 lists the values of $F$ and indicates which of these values represents a significant departure from zero. Those values that do not depart from zero are consistent with random mating for the species. Only the ramet populations 
TABLE 7. Population genetics statistics. Calculation of the fixation index by population. Values not calculated for invariant loci. Asterisks after values $=$ chi-square test. No asterisk indicates that the locus did not differ significantly from 0 and thus suggests random mating. ${ }^{*}$ indicates significance at the $P<0.05$ level; ${ }^{* *}$ indicates $P<0.01$ level; *** indicates $P<0.001$ level.

\begin{tabular}{|c|c|c|c|c|c|c|}
\hline \multicolumn{7}{|c|}{ Cystopteris bulbifera } \\
\hline $\begin{array}{l}\text { Popu- } \\
\text { lation } \\
\text { num- } \\
\text { ber }\end{array}$ & PGI-2 & IDH & $\mathrm{SkDH}$ & PGM-2 & TPI-2 & LAP \\
\hline 1 & 0.1806 & $0.094 \mathrm{l}$ & -0.0606 & -0.2500 & 0.1923 & 0.4582 \\
\hline 2 & $0.3836 * *$ & $0.5220 * * *$ & -0.0167 & 0.2458 & $0.3324 *$ & 0.0000 \\
\hline 3 & -0.3125 & -0.3208 & 0.0000 & -0.1053 & 0.0000 & 0.3000 \\
\hline 4 & -0.0952 & -0.3450 & -0.0952 & -0.2778 & 0.0000 & -0.0455 \\
\hline
\end{tabular}

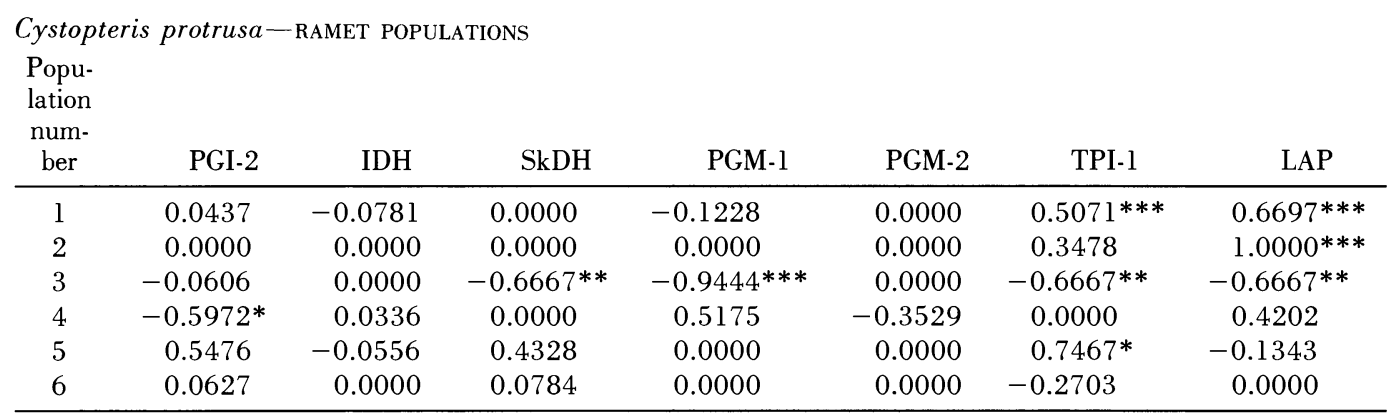

\begin{tabular}{|c|c|c|c|c|c|c|c|}
\hline $\begin{array}{c}\text { Cystop } \\
\text { Popu- } \\
\text { lation } \\
\text { num- } \\
\text { ber }\end{array}$ & ris protrusa & GENET POPU & $\mathrm{SkDH}$ & PGM-1 & PGM-2 & TPI-1 & LAP \\
\hline 1 & 0.0114 & 0.0000 & 0.0000 & 0.1944 & 0.0000 & $0.6420^{*}$ & $0.7100 * *$ \\
\hline 2 & 0.0000 & 0.0000 & 0.0000 & 0.0000 & 0.0000 & 0.4444 & 1.0000 \\
\hline 3 & 0.0000 & 0.0000 & 0.0000 & -0.5000 & 0.0000 & 0.0000 & 0.0000 \\
\hline 4 & -0.2222 & 0.5926 & 0.0000 & 0.5926 & -0.2222 & 0.0000 & 0.6857 \\
\hline 5 & 0.3500 & -0.0833 & 0.3953 & 0.0000 & 0.0000 & 0.7111 & -0.1143 \\
\hline 6 & 0.2400 & 0.0000 & 0.1204 & 0.0000 & 0.0000 & -0.2667 & 0.0000 \\
\hline
\end{tabular}

of $C$. protrusa show a large number of significant figures. Two facts suggest that these values should not be used as evidence that $C$. protrusa deviates from random mating. First, the significant values are both positive and negative with a mean of -0.0687 , a value that is very close to zero. Second, deviations from zero can be caused by oversampling of cloned genotypes. Examining the $F$ values for the genet populations shows that the number of significant figures drops to only two. Thus, the overall $F$ values (Table 7 ) indicate that breeding systems for both diploid species conform to random mating models.

Genetic analyses of sporophytic populations can be correlated with antheridiogen data and measures of genetic load to draw conclusions about the breed- ing systems of diploid members of the $C$. tennesseensis complex. Antheridiogen response data indicate that $C$. protrusa should be outcrossing while C. bulbifera should be inbreeding. Genetic load data suggest that both diploids should be outcrossing. As discussed above, chi-square tests of fixation index values (Table 7), however, indicate that neither diploid species deviates significantly from random mating. Thus it may be that genetic load has a stronger control over fern mating systems than does possession of an antheridiogen system. By combining laboratory study of gametophytes and isozymic analyses of natural sporophytic populations we can obtain a clearer understanding of the factors controlling breeding systems among these Cystopteris species (Schneller et al., 1990). 
Although the lack of allelic variability in $C$. tennesseensis precluded the application of isozyme data to analysis of breeding systems, genetic load data do provide clues to possible reproductive modes of this tetraploid. Other studies of diploid/polyploid complexes (Masuyama, 1979; Masuyama et al., 1987), have shown that although diploid progenitors may have high genetic loads, polyploids derived from them do not. Our studies of the $C$. tennesseensis complex provided another example of this phenomenon. Isolated gametophytes of both diploids were incapable of forming sporophytes, presumably because of post-zygotic lethal genes. However, $25 \%$ of isolated C. tennesseensis gametophytes did yield sporophytes. It has been hypothesized that homoeologous chromosome sets may provide buffers against expression of lethals and thereby allow polyploids to inbreed even if their progenitors cannot (Haufler, 1989).

Our data indicate that genetic identity between the diploids is zero. Given that the enzymes we surveyed are considered to be evolutionarily conservative (Gillespie \& Kojima, 1968), the lack of similarity between Cystopteris congeners is quite remarkable. Angiosperm congeners have much higher mean genetic identity values ( 0.67 in Crawford, . 1983) than those of most ferns that have been examined (0.33 in Soltis \& Soltis, 1989). For Bommeria, Haufler (1985) suggested that the low genetic identity among congeners could indicate that the morphological characters uniting the species resulted through convergent evolution and, therefore, that this genus was not monophyletic. Few would dispute, however, the clear relatedness of Cystopteris species. Apparently, the lack of homology between diploid genomes observed in the cytogenetic study extends to the isozyme data as well. Thus, these data support alternative hypotheses that either (1) speciation in ferns may be accompanied by greater isozymic divergence than is typical for angiosperms (Haufler, 1987), or (2) that most congeneric fern species diverged prior to most angiosperm congeners (Soltis \& Soltis, 1989).

The extraordinary genetic divergence of the diploids ensures a fixed heterozygote pattern for all enzymes in the derived allotetraploid. Yet, as introduced above, there is variability among individuals of C. tennesseensis (Figs. 10-12). These variants do not segregate among gametophytic progeny (Fig. 13), and are a direct reflection of the variability observed among diploid populations. In $\mathrm{As}$ plenium, Werth et al. (1985b) used such information to propose recurring origins of the allopolyploids. It seems clear that $C$. tennesseensis originated more than once; but, in contrast to the situation in Asplenium, there does not seem to be any geographic pattern to these variants. The lack of evidence for gene silencing and the fact that no orphan alleles were detected also suggests recent origins.

\section{SYSTEMATICS}

The current investigation did not result in revision of the current systematic treatment of members of the $C$. tennesseensis complex. It was possible, however, to clarify the genetics of species boundaries and identify biological factors that have contributed to confusion in species circumscriptions. Perhaps the most significant factor blurring the boundaries between species is the formation of interspecific backcross hybrids. We collected and positively identified hybrids between $C$. tennesseensis and each of its diploid progenitors. These sterile triploids are morphologically intermediate between the sexual species and, if they are not removed from consideration, can bridge the morphological gaps between what are otherwise reasonably distinct taxonomic entities.

When not confounded by hybrids, a suite of qualitative features clearly discriminates $C$. protrusa from $C$. bulbifera (presence or absence of glandular trichomes and bulblets, clear differences in rhizome characteristics). In addition, we have demonstrated genetically regulated differences in quantitative leaf features (Table 3, Fig. 1) and significant differences in spore size between diploids and tetraploids (Table 1). Thus, although the characters are subtle, it is possible to identify each species through awareness of cryptic morphological characteristics and recognition of backcross hybrids. If pteridologists hope to resolve significant evolutionary units it will be necessary to consider suites of qualitative differences, which are sometimes cryptic.

Cryptic features are even more important in the identification of tetraploid $C$. tennesseensis than they are in the diploids. Especially significant are spore characteristics, both in terms of detecting spore abortion in backcross hybrids and calculating size measurements for positive identification of ploidy level (Table 1). Somewhat problematic is our observation that spores of autotriploid $C$. protrusa can appear normal and can be quite large (Haufler et al., 1985). It is therefore important to consider the mean and standard deviation in developing an accurate assessment of the spore size (and thus the ploidy) of individual specimens.

Given the large genetic distance between the diploid congeners in the $C$. tennesseensis complex, 
it is probable that they have been phylogenetically isolated from each other for a long time and may represent systematic poles of the genus. The magnitude of the genetic distance between the two diploid species might also lead to the conclusion that hybrids between them should be rare and allopolyploid derivatives unsuccessful. Stebbins (1980) suggested that most successful polyploids are not strict autopolyploids or allopolyploids, but occupy a position somewhere between these extremes. Yet, our evidence indicates that even the highly differentiated $C$. protrusa and $C$. bulbifera have a history of recurring hybridizations and allopolyploid initiation. The derivative allotetraploid C. tennesseensis appears to be a successfully fledged and vigorous young species. It is quite widespread, is beginning to extend beyond the region of origin, and appears to be exploiting a niche that is not inhabited by either parent: neither diploid is found in the drier, more disturbed localities characteristic of $C$. tennesseensis.

\section{ConClusions}

Morphometric, chromosomal, and isozymic analyses of the $C$. tennesseensis complex support the taxonomic treatment originally proposed by Shaver (1954). The present studies document the genetic distinctness of the diploids $C$. protrusa and $C$. bulbifera and confirm the hybrid origin of the tetraploid C. tennesseensis. Considering the limited geographic range of the tetraploid, its sympatry with its parental diploids, and the lack of gene silencing, it appears that this allotetraploid is of relatively recent origin(s). Our studies have also pinpointed why these three species continue to be misidentified and misinterpreted taxonomically. First, the diploid species have a rather plastic morphology that, though genetically determined, is subtle and may be modified by environmental conditions. Second, there are autotriploid individuals of $C$. protrusa that expand the range of variability for that diploid (Haufler et al., 1985). Third, outcrossing breeding systems (driven by antheridiogen systems and/or high genetic loads) may contribute to frequent formation of backcross hybrids. These sterile triploid individuals span the morphological gaps between species, obscuring the boundaries that separate these genetically discrete taxa. Fourth, through recurring allopolyploid events, C. tennesseensis has incorporated much of the genetic variability of the diploids into its populations. As a result, positive identification of taxa in this complex depends on observations of cryptic spore and leaf features.

\section{Literature Cited}

ANDERSSON-KoTTö, I. 1930. Variegation in three species of ferns. Z.I.A.V. (Molec. Gen. Genetics) 56: 115 201

AuquiÈre, J. P. \& P. Moens. 1973. Développment due gamétophyte et vascularisation du jeune sporophyte dans le genre Cystopteris. Cellule 70: 136159.

Blasdell, R. F. 1963. A monographic study of the fern genus Cystopteris. Mem. Torrey Bot. Club 21: $1-102$.

Britton, D. M., W. G. Stewart \& W. J. Cody. 1984 Cystopteris protrusa, creeping fragile fern, an addition to the flora of Canada. Canad. Field-Naturalist 99: 380-382.

Crawford, D. J. 1983. Phylogenetic and systematic inferences from electrophoretic studies. Pp. 257287 in S. D. Tanksley \& T. J. Orton (editors), Isozymes in Plant Genetics and Breeding, Part A. Elsevier Science Publishers, Amsterdam.

Gastony, G. J. 1988. The Pellaea glabella complex: electrophoretic evidence for the derivations of the agamosporous taxa and a revised taxonomy. Amer. Fern J. 78: 44-67.

— \& L. D. Gottlieb. 1982. Evidence for genetic heterozygosity in a homosporous fern. Amer. J. Bot. 69: $634-637$.

Gillespie, J. H. \& K. Kojima. 1968. The degree of polymorphisms in enzymes involved in energy production compared to that in nonspecific enzymes in two Drosophila ananassae populations. Proc. Nat. Acad. Sci., U.S.A. 61: 582-585.

Hamrick, J. L., Y. B. Linhart \& J. B. Mitton. 1979. Relationships between life history characteristics and electrophoretically detectable genetic variation in plants. Ann. Rev. Ecol. Syst. 10: 173-200.

Haufler, C. H. 1985. Enzyme variability and modes of evolution in the fern genus Bommeria. Syst. Bot. 10: $92-104$.

1987. Electrophoresis is modifying our concepts of evolution in homosporous pteridophytes. Amer. J. Bot. 74: 953-966.

- 1989. Towards a synthesis of evolutionary modes and mechanisms in homosporous pteridophytes. Biochem. Syst. Ecol. 17: 109-115.

- \& T. A. RaNKER. 1985. Effects of differential antheridiogen response on evolutionary mechanisms in Cystopteris. Amer. J. Bot. 72: 659-665.

\& D. E. Soltis. 1984. Obligate outcrossing in a homosporous fern: field confirmation of a laboratory prediction. Amer. J. Bot. 71: 878-881.

- \& 1986. Genetic evidence suggests that homosporous ferns with high chromosome numbers are diploid. Proc. Nat. Acad. Sci., U.S.A. 83: 4389-4393.

\& C. R. WERTh. 1986. Deciphering differences in the evolutionary histories of polyploid fern species. Amer. J. Bot. 73: 736

, M. D. Windham, D. M. BRitton \& S. J. RoBINSON. 1985. Triploidy and its evolutionary significance in Cystopteris protrusa. Canad. J. Bot. 63: $1855-1863$.

Hickey, R. J., S. I. Guttman \& W. H. Eshbaugh. 1989. Evidence for post-translational modification of triose phosphate isomerase (TPI) in Isoëtes (Isoëtaceae). Amer. J. Bot. 76: 215-221. 
LLOYD, R. M. 1974. Reproductive biology and evolution in the Pteridophyta. Ann. Missouri Bot. Gard. 61: 318-331.

Lovis, J. D. 1977. Evolutionary patterns and processes in ferns. Adv. Bot. Res. 4: 220-415.

Masuyama, S. 1979. Reproductive biology of the fern Phegopteris decursive-pinnata I. The dissimilar mating systems of diploids and tetraploids. Bot. Mag. (Tokyo) 92: 275-289.

K. Mitui \& N. NaKato. 1987. Studies on intraspecific polyploids of the fern Lepisorus thunbergianus (3). Mating system and the ploidy. J. Jap. Bot. 62: 1-11.

MCGregor, R. L. 1950. Two varieties of Cystopteris fragilis. Amer. Fern J. 40: 201-207.

Moran, R. C. 1982. Cystopteris tennesseensis in Illinois. Amer. Fern J. 72: 93-95.

NAKAI, T. 1933. Notes on Japanese ferns. IX. 1. A new classification of Japanese Aspidium, with special view to the spores and connective cells. 2. Descriptions and amendments for East-Asiatic ferns. Bot. Mag. (Tokyo) 47: 15l-186.

Pichi-Sermolli, R. E. G. 1977. Tentamen Pteridophytorum genera in taxonomicum ordinem redigendi. Webbia 31: 313-512.

Profumo, P. 1969. The gametophytes of Cystopteris fragilis and Cystopteris dickieana. Webbia 23: 317328.

Ranker, T. A. \& A. F. Schnabel. 1986. Allozymic and morphological evidence for a progenitor-derivative species pair in Camassia (Liliaceae). Syst. Bot. ll: 433-445.

Schneller, J. J., C. H. Haufler \& T. A. Ranker. 1990. Antheridiogen and natural gametophyte populations. Amer. Fern J. (in press).

Shaver, J. M. 1950. A new fern, Cystopteris tennesseensis, sp. nov. from Tennessee. J. Tennessee Acad. Sci. 25: 106-113.

- 1954. Ferns of the Eastern Central States with Special Reference to Tennessee. General Publishing Co., Toronto.

Soltis, D. E., C. H. Haufler, D. C. Darrow \& G. J. GASTONY. 1983. Starch gel electrophoresis of ferns: a compilation of grinding buffers, gel and electrode buffers, and staining schedules. Amer. Fern J. 73: $9-27$.

— \& P. S. Soltis. 1989. Polyploidy, breeding systems, and genetic differentiation in homosporous pteridophytes. Pp. 24l-258 in D. E. Soltis \& P. S. Soltis (editors), Isozymes in Plant Biology. Dioscorides Press, Portland, Oregon.

StebBins, G. L. 1980. Polyploidy in plants: unsolved problems and prospects. Pp. $495-520$ in W. H. Lewis (editor), Polyploidy: Biological Relevance. Plenum Press, New York.

Stein, D. \& D. S. BarRington. 1990. Recurring hybrid formation in a population of Polystichum $\times$ potteri: evidence from chloroplast DNA comparisons. Ann. Missouri Bot. Gard. (this volume).

W AGNER, W. H., JR. 1954. Reticulate evolution in the Appalachian aspleniums. Evolution 8: 103-118. . 1971. Evolution of Dryopteris in relation to the Appalachians. Pp. 147-192 in P. Holt (editor), The Distributional History of the Biota of the Southern Appalachians. Part II. Flora. Res. Div. Mono. 2, Virginia Polytechnic Inst. and State Univ.

WeEden, N. F. 1983. Plastid isozymes. Pp. 139-156 in S. D. Tanksley \& T. J. Orton (editors), Isozymes in Plant Genetics and Breeding, Part A. Elsevier Science Publishers, Amsterdam.

Werth, C. R., S. I. Guttman \& W. H. Eshbaugh. 1985a. Electrophoretic evidence of reticulate evolution in the Appalachian Asplenium complex. Syst. Bot. 10: 184-192.

$$
\text { \& }
$$

1985b. Recurring origins of allopolyploid species in Asplenium. Science 228: 731-733. 